\title{
Lipoma infiltrativo espontâneo em porquinho-da-índia (Cavia porcellus)*
}

\section{Spontaneous infiltrative lipoma in Guinea Pig (Cavia porcellus)}

\author{
Francisco Canindé Lopes, ${ }^{* *}$ Idalécio Pacífico da Silva, ${ }^{* *}$ Taciana de Melo Fernandes Silva, ${ }^{* *}$ Robério Gomes Olinda, ${ }^{* * *}$, \\ Aline Cavalcante da Costa, ${ }^{* * *}$ Jael Soares Batista, ${ }^{* * *}$ Carlos Iberê Alves Freitas ${ }^{* * * *}$
}

\begin{abstract}
Resumo
Os lipomas infiltrativos diferenciam-se dos não infiltrativos por invadirem tecidos adjacentes como tendões, músculos, cápsulas articulares e ossos. Objetivou-se neste estudo relatar o primeiro caso de lipoma em caráter infiltrativo espontâneo em um Cavia porcellus fêmea, com idade aproximada de 8 anos e peso de $950 \mathrm{~g}$. Ao exame clínico observou-se uma massa subcutânea que se estendia por sobre as costelas na região toracoabdominal esquerda pesando $185 \mathrm{~g}$ (correspondente a $19,47 \%$ do seu peso corpóreo), coloração branca/amarelada, aspecto gorduroso, macio à palpação e com sinais de aderência. A punção aspirativa por agulha fina evidenciou esfregaços não corados de aspecto úmido com gotículas brilhantes que não se secavam completamente ao ar, compatível com tecido gorduroso. O diagnóstico definitivo para lipoma foi confirmado pelo histopatológico, que revelou adipócitos bem diferenciados de diâmetros irregulares, alguns mal circunscritos e uma área com infiltração de adipócitos entre as fibras muculares, mostrando tratar-se de uma variante infiltrativa que é bastante rara em algumas espécies. Conclui-se que o Cavia porcellus é uma espécie que pode desenvolver lipomas de caráter infiltrativo, devendo-se suspeitar de sua presença sempre que existir massas subcutâneas bem circunscritas e aderidas.
\end{abstract}

Palavras-chave: cobaio, neoplasia, cirurgia, roedor.

\begin{abstract}
Infiltrative lipomas are differentiated of the non infiltrative by invade adjacent tissues such as tendons, muscles, bones and joint capsules. This study aimed to report the first case of spontaneous infiltrative nature lipoma in Cavia porcellus female, approximately 8 years old and weighing $950 \mathrm{~g}$. Clinical examination revealed a subcutaneous mass that stretched on the ribs on the left thoracoabdominal region weighing $185 \mathrm{~g}$ (corresponding to $19.47 \%$ of body weight), color white / yellowish, greasy appearance, soft to palpation and signs of adhesion. A fine needle aspiration biopsy smears showed unstained wet-looking with shiny droplets that are not completely dried in air, compatible with fatty tissue. Definitive diagnosis for lipoma was confirmed by histopathological examination, which revealed differentiated adipocytes of irregular diameters some poorly circumscribed and an area with infiltration of adipocytes between fibers muculares. Showing that it is a variant of infiltrative which is quite rare in some species. It is concluded that the Cavia porcellus is a species that can develop infiltrative lipomas, and one should suspecting their presence whenever there well-circumscribed subcutaneous masses adhered.
\end{abstract}

Keywords: Guinea pig, neoplasms, surgery, rodent.

\section{Introdução}

O Cavia porcellus é um roedor muito dócil, utilizado como animal de estimação, de laboratório e ainda como especiaria culinária em sua região de origem, as montanhas andinas. É um animal amplamente utilizado como modelo experimental em estudos e pesquisas sobre anafilaxia, hipersensibilidade retardada, genética, cetoacidose, neuropatias ópticas, amebíase, escorbuto, leucemia, encefalomielite alérgica, colite ulcerativa, doenças infecciosas, imunologia e nutrição (Harkness e Wagner, 1993).

Estudos sobre ocorrências de neoplasias no Cavia porcellus têm revelado uma baixa incidência nesta espécie. Entre os anos de 1916 e 1937, onde foram examinadas 15.000 cobaias, nenhuma apresentou neoplasias (Williams, 1991; Harkness e Wagner, 1993). Entretanto, a incidência do problema nestes animais após os três anos de vida pode chegar a $30 \%$, e as neoplasias mais comuns são as do trato respiratório, seguidas pelas de pele e tecido subcutâneo (Manning, 1976). Mais recentemente foi diagnosticado pela primeira vez um lipossarcoma palpebral no olho direito de um Cavia porcellus de 18 meses de idade (Quinton, 2013). O lipoma é o tumor benigno de origem mesenquimal, possui crescimento lento, são bem circunscritos, possuem mobilidade e causam mínima reação inflamatória. Porém, dependendo da região, podem causar desconfortos com seu crescimento (Fineman, 2004; North e Banks, 2009).

O lipoma clássico, "não infiltrativo", é visto na maioria das espécies domésticas, mas é considerado comum apenas em

\footnotetext{
*Recebido em 10 de maio de 2013 e aceito em 24 de setembro de 2013.

**Doutorando em Ciência Animal, Laboratório de Patologia Veterinária, Universidade Federal Rural do Semi-Árido (UFERSA), Mossoró, RN, Brasil. Autor para correspondência: E-mail - fcoclopes@bol.com.br.

***Aluno de graduação em Medicina Veterinária, UFERSA, Mossoró, RN, Brasil.

****Professor doutor adjunto do Departamento de Ciências Animais, UFERSA, Mossoró, RN, Brasil.
} 
cães e gatos e incomum em equinos e bovinos. Ele não tem característica de ser invasivo ou agressivo e nem de produzir metástase para tecidos e/ou órgãos distantes, representando $16 \%$ dos tumores benignos cutâneos nos cães. Outros animais que podem ser afetados incluem periquitos, ratos, cobaios, camundongos, ovinos, suínos e primatas (Silveira et al., 2006).

É crescente o interesse nos estudos sobre neoplasias de animais exóticos e selvagens na prática veterinária e, apesar de sua importância, são escassos os estudos nesta área. Assim, com a finalidade de contribuir para o conhecimento das neoplasias que acometem o Cavia porcellus, o presente trabalho tem como objetivo relatar a ocorrência e os principais achados anátomohistopatológicos de um lipoma infiltrativo nesta espécie.

\section{Relato de caso}

O estudo foi realizado a partir de um exemplar de Cavia porcellus, fêmea, com idade estimada de 8 anos e peso de $950 \mathrm{~g}$, que vivia em cativeiro junto com outros 11 animais da mesma espécie, dividindo um recinto com dimensões $120 \times 100 \times 60 \mathrm{~cm}$, alimentado com ração comercial para coelhos e restos de legumes. $\mathrm{Na}$ anamnese foi informado que o animal tinha apetite normal. Entretanto, há algumas semanas estava apresentando comportamento atípico, mostrando-se quieto, movimentando-se menos e isolando-se dos outros animais do recinto. No exame clínico foi observado que o animal apresentava uma massa subcutânea que se estendia por sobre as costelas na região toracoabdominal esquerda (Figura 1). Pela palpação, percebeuse que a mesma era bem circunscrita, macia, compatível com tecido gorduroso e encontrava-se aderida. Para diagnóstico inicial foi realizada Punção Aspirativa com Agulha Fina (PAAF), revelando esfregaços não corados de aspecto úmido com gotículas brilhantes que não se secavam completamente ao ar, compatível com tecido gorduroso. O animal foi encaminhado para cirurgia, procedendo-se a exérese da massa tumoral (Figura 2). Foi usado sulfato de atropina na dosagem de $0,05 \mathrm{mg} /$ $\mathrm{kg}$, cloridrato xilazina na dose de $2 \mathrm{mg} / \mathrm{kg}$, como medicação préanestésica. Indução através da aplicação de cloridrato cetamina na dose de 20mg/kg (Heard, 2003; Huerkamp, 2008; Bauck, 2008), e sob anestesia local infiltrativa perilesional utilizando-se cloridrato de lidocaína $1 \%$ com vasoconstrictor na dose de $9 \mathrm{mg} /$ kg. Realizou-se a exérese do tumor através de incisão elipsóide em cunha, divulsão ao redor da massa tumoral de modo a obter margens e base livre, e finalmente retirada. A hemostasia foi realizada por pinçamento e compressão de pequenos vasos. Por fim, foi feita redução do espaço morto com fio catgut cromado 3-0 em pontos zigzag e sutura de pele a pontos simples contínuos com fio náilon 3-0. A massa tumoral foi colocada em solução fixadora de formol a $10 \%$. A partir do material fixado, colheu-se um fragmento para processamento com técnica histológica de rotina e coloração com Hematoxilina-Eosina.

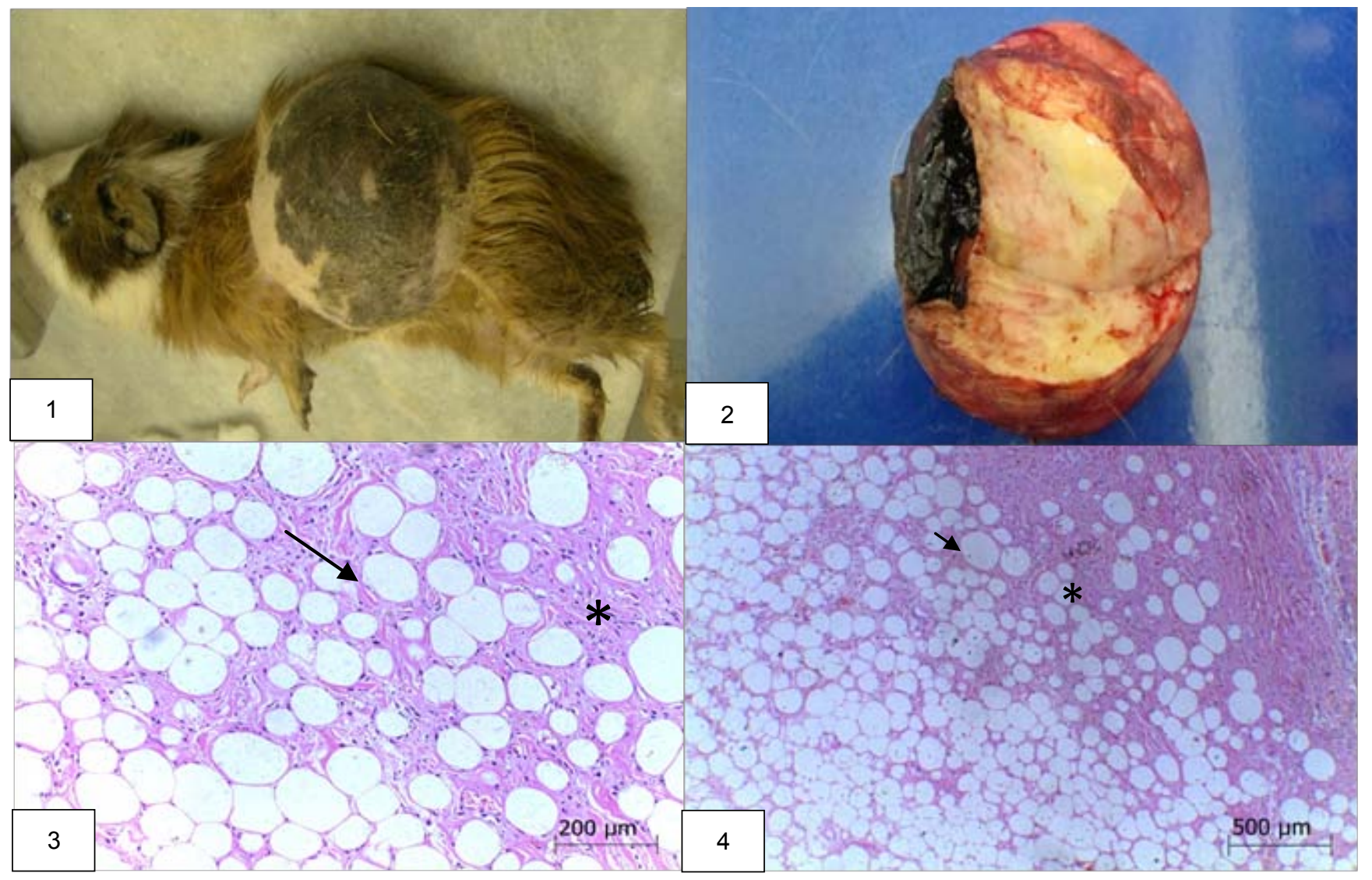

Figura 1: Cavia porcellus. Nódulo subcutâneo na região torácica do lado esquerdo de Cavia porcellus, de 8 anos. Figura 2: Cavia porcellus. Aspecto macroscópico do nódulo subcutâneo de coloração amarelada e aspecto gorduroso. Figura 3: Cavia porcellus. Microscopia do tumor constituído por

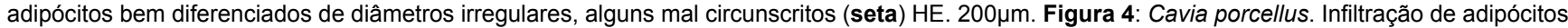
entre as fibras muculares (asterisco) HE. 500 $\mu \mathrm{m}$. 


\section{Discussão}

A punção aspirativa por agulha fina evidenciou esfregaços não corados de aspecto úmido com gotículas brilhantes que não se secavam completamente ao ar compatível com tecido gorduroso, confirmando a suspeita dos achados clínicos sugestivos de lipoma (Raskin, 2010). Após o procedimento cirúrgico, a massa tumoral retirada mediu $21,3 \mathrm{~cm}$ de diâmetro, tinha aspecto gorduroso, macio à palpação, coloração amarelada e pesou $185 \mathrm{~g}$, correspondendo a $19,47 \%$ do peso vivo do animal. Uma incisão longitudinal sobre a peça operatória revelou que se tratava de uma massa tecidual amarela, semelhante a tecido adiposo (Figura 2). A massa tumoral, quando colocada em solução fixadora (formol 10\%), submergiu, demonstrando uma característica peculiar dos lipomas. $\mathrm{O}$ exame histopatológico revelou que o tumor era constituído por adipócitos bem diferenciados de diâmetros irregulares, alguns mal circunscritos (Figura 3), uma área com infiltração de adipócitos entre as fibras muculares (Figura 4), confirmando em definitivo o diagnóstico clínico e o resultado da biopsia aspirativa sugestiva para lipoma, mostrando tratar-se de uma variante infiltrativa que é bastante rara em algumas espécies, o qual pela primeira vez está sendo descrito no Cavia porcellus.

As características macroscópicas encontradas no tumor do animal estudado são claras e similares aos normalmente encontrados, que possuem aspecto de um tumor constituído de tecido adiposo bem diferenciado, de coloração amarela e envolto por uma fina cápsula de tecido conjuntivo. Mas, o que chama atenção foi o tamanho da massa tumoral e o fato de que o mesmo tinha característica de invadir o tecido muscular adjacente dando um aspecto de estar fixado ou se infiltrando. Os lipomas infiltrativos são semelhantes aos lipomas clássicos, podendo apresentar-se maiores, mais firmes, pouco delimitados e sua principal característica é invadir o tecido adjacente como tendões, músculos, cápsulas articulares e ossos (Patnaik et al., 1984; Oliveira et al., 2006; Tungenwar et al., 2010). Os lipomas infiltrativos ocasionalmente podem conter outros tecidos como cartilagem (condrolipoma), vasos sanguíneos (angiolipoma) e colágeno (fibrolipoma), e alguns se apresentam ainda como massas globulares gordurosas, não dolorosas, móveis e macias à palpação, e são facilmente removíveis (Hargis, 1998; Reavill, 2004; Godoy, 2006). Algumas vezes a cápsula pode estar ausente ou rompida (Epivatianos et al., 2000). O estroma pode apresentar-se fibroso dividindo a gordura em lóbulos e esses septos contêm vasos sanguíneos de pequeno calibre (Rodrigues et al., 1996).

Apesar de ser uma patologia bastante conhecida em várias outras espécies, o lipoma não é comum no Cavia porcellus e pode ser confundido com outras neoplasias. Pesquisando neoplasias nesta espécie, Papanicolaou e Olcott realizaram necrópsia em 7000 cobaias encontrando apenas 100 neoplasias; e Mosinger, após 5540 necrópsias, encontrou apenas cinco neoplasias. Isso ocorre porque o plasma do Cavia porcellus possui substâncias com propriedades inibidoras do crescimento tumoral (Manning, 1976), sendo que o responsável por isso é um fator antitumoral, a "asparaginase", das cobaias (Williams, 1991). Em outras espécies como em cães domésticos, as neoplasias cutâneas são frequentes na rotina médico-veterinária, e os sinais clínicos podem variar de acordo com a extensão da lesão, comportamento biológico e o tipo tumoral (Fineman, 2004).

Na microscopia podemos observar que a variante infiltrativa aqui encontrada caracteriza-se por uma proliferação de adipócitos bem diferenciados e com pouca irrigação sanguínea no interior de uma massa bem circunscrita com adipócitos de aparência normal, mas que se infiltra no tecido muscular adjacente. Entretanto, a diferença entre os lipomas infiltrativos e os lipomas tradicionais pode ser dificultada ou impossível de realizar em biópsias feitas com pequenos fragmentos ou superficiais (Godoy, 2006).

O lipoma infiltrativo, descrito pela primeira vez na medicina veterinária em 1979, é considerado uma neoplasia incomum nos cães e rara em gatos, equinos e bovinos (Finnie et al., 1979; Gross et al., 2005). Numa avaliação de 214 lipomas infiltrativos em cães e gatos, os locais mais afetados foram: membro anterior $(24,8 \%)$, tórax $(22,0 \%)$, membro posterior $(16,8 \%)$, abdômen $(10,3 \%)$, cabeça $(9,3 \%)$, períneo $(7,0 \%)$, pescoço $(6,1 \%)$ e dorso $(2,8 \%)$ (Goldschmidt e Shofer, 1992).

O animal de nosso estudo apresentava obesidade, idade avançada, dieta com alto nível de energia e sedentarismo. Estes fatores já foram igualmente observados, onde o lipoma geralmente está associado ao sedentarismo, superalimentação e hipotireoidismo subclínico provocado por baixos teores de iodo da dieta (Werner et al., 1998; Godoy, 2006). O tratamento estabelecido neste estudo foi a exérese cirúrgica, e apesar do tamanho exagerado da massa tumoral, o procedimento cirúrgico transcorreu sem maiores dificuldades ou complicações, o que é comum para este tipo de neoplasia. Este método também é adotado pelos autores onde ressaltam que o tratamento dos lipomas é feito pela excisão cirúrgica conservadora, onde normalmente as cirurgias são simples, e quando retirados totalmente têm prognóstico favorável, ocorrendo raras recidivas (North e Banks, 2009).

Clinicamente, os diagnósticos diferenciais do lipoma infiltrativo são os mesmos do lipoma clássico, e incluem todos os tumores que ocorrem na forma de nódulos. Histologicamente, os lipomas infiltrativos devem ser distinguidos dos lipomas não infiltrativos, dos lipossarcomas, de lipomatose difusa idiopática e dos aumentos na quantidade de gordura localizada devido à obesidade (Finnie et al., 1979; Gross et al., 2005). Destarte, através do diagnóstico histopatológico, pode-se afirmar que se trata de um caso raro de lipoma infiltrativo em Cavia porcellus. Apesar de retirar todo o tumor, o prognóstico foi reservado, pois não se sabe como essa variante infiltrativa se comporta nessa espécie. Sabe-se que o prognóstico do lipoma infiltrativo em cães geralmente é reservado, pois em $36 \%$ dos casos ocorrem recidiva (Seiler, 1981; Mckeever et al,1982; Sischo et al., 1989; Silveira et al., 2006).

\section{Conclusão}

O Cavia porcellus é uma espécie que pode desenvolver lipomas de caráter infiltrativo, devendo ser considerado no diagnóstico diferencial clínico-histopatológico das neoplasias subcutâneas, suspeitando-se da sua presença sempre que existir massas subcutâneas bem circunscritas e aderidas. 


\section{Referências}

BAUCK, L; BIHUN. C. "Rodent anesthesia" in Longley L (Ed.), Anesthesia of exotic pets, Saunders, 2008, p. 59-80.

EPIVATIANOS A, MARKOPOULOS AK, PAPANAYOTOU P. Benign tumors of adipose tissue of the oral cavity: a clinicopathologic study of 13 cases. J. Oral Maxillofac Surg. 2000 v. 58, n.10, p. 1113-1117. FINNIE, J. W. \& BOSTOCK, D. E. Skin neoplasia in dogs. Australian Veterinary Journal, v. 55, p. 602-604, 1979.

FINEMAN, L. S. Tumores da pele e do tecido subcutâneo em cães e gatos. In: ROSENTHAL, R. C. Segredos em oncologia veterinária. Porto Alegre. Artmed, p. 169-76, 2004.

GODOY, S. N. Psittaciformes. In: CUBAS, Z. S.; SILVA, J. C. R.; CATÃO-DIAS, J. L. Tratado de Animais Selvagens - Medicina Veterinária. São Paulo: Rocca, 2006. cap. 16, p. 222-247.

GOLDSCHMIDT, M. H. \& SHOFER, F. S. Skin tumors of the dog and cat. Oxford: Pergamon, 1992. 316 p.

GROSS, T. L.; IHRKE, P. J.; WALDER, E. J.; AFFOLTER, V. K. Skin Diseases of the Dog and Cat: Clinical and Histopathologic Diagnosis.2nd ed. Blackwell Science Ltd, 2005. 895 p.

HARGIS, A. M. Sistema Tegumentar. In: CARLTON, W. W.; McGAVIN, M. D. Patologia Veterinária Especial de Thomson. 2. ed. Porto Alegre: Artmed, 1998. cap.11, p. 486-540.

HARKNESS, J. E.; WAGNER, J. E. Biologia e clínica de coelhos e roedores. 3. ed. São Paulo: Roca, 1993.

HEARD, D. J. (2003) "Anesthesia, Analgesia, and Sedation of Small Mammals" in CARPENTER J. W., Quesenberry K. E. (Ed.), Ferrets, Rabbits and Rodents Clinical Medicine and Surgery, $2^{\mathrm{a}}$ ed., Saunders, p. 356-368.

HUERKAMP, M. J. (2008) "Rodent anesthesia" in Longley L (Ed.), Anesthesia of exotic pets, Saunders, 59-80

MCKEEVER, P. J.; GRINDEM, C. B.; STEVENS, J. B. et al. Canine cutaneous lymphoma. Journal of American Veterinary Medicine Association, v.180, p. 531-536, 1982.

MANNING, P. J. Neoplastic diseases. In: WAGNER, J. E.; MANNING, P. J. The biology of guinea pig.Academic Press, 1976. NORTH, S.; BANKS, T. Tumours of skin and subcutaneous tissues. In:_. Introduction to Small Animal Oncology. 1 ed. London: Sauders Elsevier, p. 172-182, 2009.
OLIVEIRA, F. S.; MARTINS, L. L.; DELFINI, A.; FARIA-JUNIOR, D. Exérese de lipoma em papagaio-verdadeiro (Amazona aestiva). Acta Scientiae Veterinariae, Porto

Alegre, v. 34, n. 2, p. 201-203, 2006.

PATNAIK, A. K.; EHLER, W. J. \& MACEWEN, E. G. Canine cutaneous mast cell tumor: morphologic grading and survival time in 83 dogs. Veterinary Pathology, v. 21, p. 469-474, 1984.

QUINTON, J. F.; OLIVER, F; DALLY, C. A case of well-differentiated palpebral liposarcoma in a Guinea pig (Cavia porcellus). Vet Ophthalmol. Suppl 1, p.155-159, 2013.

REAVILL, D. R. Tumors of pet birds. Veterinary Clinics of North America: Exotic Animal Practice, Orlando, v. 7, n. 3, p. 537-560, 2004.

RASKIN R.E. Lymphoid System, p.77-122. In: Raskin R.E. \& Meyer D.J. (Eds), Canine and Feline Cytology. 2nd ed. Elsevier, St Louis, 2010.

RODRIGUES CB, SOUZA CS, MORAES Jr EF. Caso Incomum de Lipoma Associado ao Nervo Mentoniano - Uma revisão. Rev. FOB, 1996, v. 4, n. 3/4, p. 1-6.

SILVEIRA, L. G. M.; CUNHA, F. M.; MARZANO, T. F. et al. Estudo crítico de neoplasias cutâneas em cães. Revista Inst. Ciência e Saúde, 24(3):196-73, 2006.

SEILER, R. J. Granular basal cell tumors in the skin of three dogs: a distinct histopathologic entity. Veterinary Pathology, v. 18, p. 2329, 1981.

SISCHO, W. M. et al. Regional distribution of 10 common skin diseases in dogs. Journal of American Veterinary Medicine Association, v. 195, p. 752-756, 1989.

TUNGENWAR, P. N.; BAKHSHI, G. D.; SURYAWANSHI, M. M. et al. Vulvar lipoma - a rare case report. Bombay Hospital Journal, v. 52, n.1, p. 105-107, 2010.

WERNER, P. R.; CHIQUITO, M.; PACHALY, J. R. Estudo retrospectivo das neoplasias diagnosticadas em animais selvagens ou exóticos pelo Serviço de Patologia do Hospital Veterinário da Universidade Federal do Paraná entre 1974 e 1996. Archives of Veterinary Science, Curitiba, v. 3, n.1, p. 39-44, 1998.

WILLIAMS, D. L. Tumors of laboratory mammals, birds and exotic animals. In: WHITE, R. A. S. Manual of Small Animal Oncology. BSAVA, Grã-Bretanha, 1991. 